\title{
Thermophilic co-digestion of organic fraction of municipal solid wastes with FOG wastes from a sewage treatment plant: Reactor performance and microbial community monitoring
}

\author{
Lucia Martín-González $^{\mathrm{a}}$, Rita Castro ${ }^{\mathrm{b}}$, M.Alcina Pereira ${ }^{\mathrm{b}}$, M.Madalena Alves $^{\mathrm{b}}$, Xavier Font $^{\mathrm{a}}$, \\ Teresa Vicent ${ }^{\mathrm{a}, 1, *}$ \\ a Departament d'Enginyeria Química, Universitat Autònoma de Barcelona, 08193 Bellaterra, Spain \\ ${ }^{\mathrm{b}}$ Institute for Biotechnology and Bioengineering, Centre of Biological Engineering, University of Minho, 4710-057 Braga, Portugal
}

\section{A R T I C L E I N F O}

\section{Article history:}

Received 10 November 2010

Received in revised form 18 January 2011

Accepted 19 January 2011

Available online 25 January 2011

\section{Keywords:}

Thermophilic anaerobic co-digestion

OFMSW

FOG wastes

PCR-DGGE

Microbial diversity

\begin{abstract}
A B S T R A C T
Working at thermophilic conditions instead of mesophilic, and also the addition of a co-substrate, are both the ways to intend to improve the anaerobic digestion of the source-collected organic fraction of municipal solid wastes (SC-OFMSW). Addition of sewage treatment plant fat, oil and grease wastes (STP-FOGW), that are nowadays sent to landfill, would represent an opportunity to recover a wasted methane potential and, moreover, improve the whole process. In this study, after a first period feeding only SC-OFMSW, a co-digestion step was performed maintaining thermophilic conditions. During the co-digestion period enhancements in biogas production (52\%) and methane yield (36\%) were achieved. In addition, monitoring of microbial structure by using PCR-DGGE and cloning techniques showed that bacterial community profiles clustered in two distinct groups, before and after the extended contact with STP-FOGW, being more affected by the STP-FOGW addition than the archaeal one.
\end{abstract}

(c) 2011 Elsevier Ltd. All rights reserved.

\section{Introduction}

Since the early 2000 the number of thermophilic anaerobic digestion plants treating organic wastes has increased significantly in Europe. During previous years, mesophilic processes appeared to be more stable than thermophilic ones, and operational problems, or even process failures, were noticed in lab-scale and full-scale plants when working at $55{ }^{\circ} \mathrm{C}$ (De Baere and Mattheeuws, 2010). However, throughout recent years, positive results in thermophilic anaerobic treatment of organic wastes are extensively reported in literature and main advantages of thermophilic conditions in comparison to mesophilic ones are emphasized: efficiency to treat higher loads of waste in less time; increasing of biogas production and also higher destruction of pathogenic microorganisms, that lead to a better hygienisation of solid waste material for its use on land (Ferrer et al., 2010; Kim et al., 2002).

Besides working at thermophilic temperatures, addition of co-substrates could also improve the biogas production, and even the methane yield, of a traditional anaerobic digestion process of

\footnotetext{
* Corresponding author. Tel.: +34 935812 142; fax: +34 935812013. E-mail address: teresa.vicent@uab.cat (T. Vicent).

1 Present address.
}

organic wastes (Cavinato et al., 2010; Hartmann and Ahring, 2005). Actually, some biogas plants based on co-digestion concepts are nowadays searching for wastes with higher biogas potentials. Hence, lipid-rich wastes or fat, oil and grease wastes (FOGW) stand out as a substrate of great interest due to its high theoretical methane yield (Alves et al., 2009).

FOGW from sewage treatment plants (STP-FOGW) are an example of complex fat-containing wastes that, among others, could represent an opportunity to expand the range of suitable substrates in the co-digestion field. They are commonly separated in the skimming tanks, at the first stage of the STP and, nowadays, its ensuing treatments are incineration and/or landfill disposal.

Anaerobic treatment of fat-containing wastes presents important challenges related to inhibition episodes due to long chain fatty acids (LCFA) content, or flotation/wash out problems (Alves et al., 2001; Hwu et al., 1998). Nevertheless, inhibition is, in some conditions, a reversible phenomenon (Pereira et al., 2004), and successful experiments are reported at mesophilic (Cavaleiro et al., 2009) and thermophilic temperatures (Creamer et al., 2010). Thermophilic conditions can increase the solubility of FOG wastes and, as a consequence, enhance its biodegradability (Creamer et al., 2010). Therefore, it seems clear that co-digestion of high-fat containing wastes with other biodegradable wastes, such as organic fraction of municipal solid wastes (OFMSW), would be a promising method and an opportunity that needs further investigations. 
The study of microbial communities represents another growing area of research in the field of anaerobic digestion. It is well known that, a deeper knowledge in microbial dynamics, would provide information in order to, for example, predict system performance under a given set of conditions, or design engineered systems to foster the development of specific communities (Briones and Raskin, 2003). In fact, the lack of more information regarding to differences between mesophilic and thermophilic active microbial populations has been pointed out as the main reason for several unsuccessful experiences (Ahring et al., 2002).

Focusing on lipid-rich wastes degradation processes, several works dealing with microbial populations have been published (Palatsi et al., 2010; Pereira et al., 2002b; Sousa et al., 2007) and, more specifically, works dealing with thermophilic anaerobic digestion of organic wastes that study shifts in microbial populations linked to reactor performances (Goberna et al., 2009; Weiss et al., 2008). However, to our knowledge, fewer efforts have been made in the field of thermophilic co-digestion of organic wastes with STP-FOGW.

The purpose of this work was to evaluate the effect of using STP-FOGW as a co-substrate in a thermophilic anaerobic digestion process of source-collected organic fraction of municipal solid wastes (SC-OFMSW). Therefore, two different stages were defined: first, the single-substrate stage when only SC-OFMSW was fed to the reactor and, afterwards, the co-digestion stage, when STP-FOGW was added. The whole experiment involved the study of the reactor performance, in terms of different process parameters, and also the microbial community monitoring by using PCR-DGGE, cloning and sequencing techniques.

\section{Methods}

\subsection{Experimental set-up}

Anaerobic co-digestion was carried out in a $5 \mathrm{~L}$ glass jacketed reactor connected to a thermostatic bath through which the temperature was controlled in order to maintain thermophilic conditions $\left(55^{\circ} \mathrm{C}\right)$. A detailed description of the experimental system can be found elsewhere (Martín-González et al., 2010).

\subsection{Inoculum and substrates}

Digested effluent from a thermophilic anaerobic reactor treating OFMSW and diatomaceous earth waste, from a biomethanisation and composting plant located in Terrassa (Barcelona), was used as inoculum. Total solids (TS) and volatile solids (VS) of the original sample were 275 and $110 \mathrm{~g} \mathrm{~kg}^{-1}$, respectively. Since the experiment was carried out at wet conditions, the original sample was diluted with tap water to reach 65.6 and $28.8 \mathrm{~g} \mathrm{~kg}^{-1}$, TS and VS, respectively. No volatile fatty acids (VFA) were detected.

STP-FOGW was collected from the primary skimmer of the Granollers STP (Catalunya, Spain) and was stored at $-18^{\circ} \mathrm{C}$ until use. SC-OFMSW was obtained from the municipal solid waste treatment plant Ecoparc II, in Montcada i Reixac (Catalunya, Spain) and, afterwards, it was ground and stored at $-18{ }^{\circ} \mathrm{C}$ until use. Main characteristics of both substrates are shown in Table 1.

\subsection{Experimental procedure and reactor operation}

The reactor was fed once a day, always following the same extraction/feed routine: first the established volume was extracted with a vacuum pump connected to a vessel also linked to the outlet tube, and then, straight afterwards, feed was added through the inlet channel. During the co-digestion stage, STP-FOGW and SC-OFMSW were mixed before feeding the reactor, since it is
Table 1

Characteristics of STP-FOGW and SC-OFMSW used in this study.

\begin{tabular}{lll}
\hline Parameter & STP-FOGW & SC-OFMSW \\
\hline Total solids, TS $\left(\mathrm{g} \mathrm{kg}^{-1}\right)$ & 116.6 & 373.4 \\
Volatile solids, VS $\left(\mathrm{g} \mathrm{kg}^{-1}\right)$ & 103.9 & 338.5 \\
VS/TS ratio & 0.89 & 0.90 \\
Total VFA ( $\left.\mathrm{g} \mathrm{L}^{-1}\right)$ & n.d. & $1.3 \pm 0.4$ \\
TKN $(\%$, dry basis) & $2.4 \pm 0.5$ & $3.3 \pm 0.5$ \\
TOC $(\%$, dry basis) & $55 \pm 6$ & $45 \pm 5$ \\
FOG content $(\%$, dry basis) & $50 \pm 3$ & $17 \pm 5$ \\
Free LCFA content $\left(\mathrm{mg} \mathrm{g} \mathrm{TS}^{-1}\right)$ & & \\
Myristic acid & $2.7 \pm 0.3$ & $0.57 \pm 0.12$ \\
Palmitic acid & $18 \pm 4$ & $9 \pm 3$ \\
Oleic acid & $9 \pm 1$ & $7 \pm 4$ \\
Stearic acid & $7 \pm 1$ & $9 \pm 3$ \\
\hline
\end{tabular}

important to disperse the lipids in order to avoid its propensity to form floating aggregates.

Prior to the start of the current study, the thermophilic anaerobic reactor was inoculated and, after 2 days of acclimation without feeding, the reactor started to treat SC-OFMSW. During almost a month, the reactor showed a stable performance working at an organic loading rate (OLR) of $5.3 \mathrm{~kg} \mathrm{VS} \mathrm{m}^{-3} \mathrm{~d}^{-1}$. The TS feed content was then $14 \%$ and the flow rate was fixed around $200 \mathrm{~mL} \mathrm{~d}^{-1}$, corresponding to a hydraulic retention time (HRT) of $25 \mathrm{~d}$ (data not shown). In order to develop the present experiment at wet conditions, on day 0 , TS feed content was set at $7 \%$, flow rate was increased until $310 \mathrm{~mL} \mathrm{~min}^{-1}$ and, therefore, OLR and HRT were established at $4.3 \mathrm{~kg} \mathrm{VS} \mathrm{m}^{-3} \mathrm{~d}^{-1}$ and $16 \mathrm{~d}$, respectively.

The present study lasted almost 7 months (0-193 days) and two main stages can be defined: between days 0-62 the single-substrate stage (corresponding to Period I on Table 2) was performed when only SC-OFMSW was fed to the reactor, maintaining the aforementioned operational conditions. Next, the co-digestion stage started on day 63 when STP-FOGW was added to SC-OFMSW in a ratio of 1:6 (VS:VS) and, as a consequence of the addition, OLR slightly increased to $5 \mathrm{~kg} \mathrm{VS} \mathrm{m}^{-3} \mathrm{~d}^{-1}$ and HRT decreased to $14.4 \mathrm{~d}$ (Period II). Finally, an additional period should be defined within the co-digestion stage (Period III) since, on day 168, feed ratio of STP-FOGW:SC-OFMSW (VS:VS) was raised again to reach 1:4 $\left(\mathrm{OLR}=5.3 \mathrm{~kg} \mathrm{VS} \mathrm{m}^{-3} \mathrm{~d}^{-1}\right.$, HRT $\left.=14 \mathrm{~d}\right)$ until the end of the experiment, on day 193.

Mean values of process parameters were used to describe Periods I and II in terms of reactor performance (Table 2), but only values accomplishing the following stability criteria were considered: one HRT had to be accounted for and variations in the main process parameters (VS reduction, biogas production and VFA) had to be lower than $10 \%$. Period III was considered too short to calculate reliable average values. In addition, samples for molecular analysis were collected for further microbial study during Periods I, II and III.

\subsection{Routine analysis}

TS, VS and total Kjeldahl nitrogen (TKN) were determined according to Standard Methods (APHA et al., 1999). Total organic carbon (TOC) content was determined using a commercial solids TOC analyzer (Solids TOC Analyzer, O I Analytical, USA).

VFAs (acetic, propionic, butyric, valeric and $n$-valeric acids) were determined by gas chromatography in a Hewlett Packard Chromatograph (HP 5890) equipped with a flame ionization detector (FID) and a Teknocroma (25\% NPGA, 2\% $\left.\mathrm{H}_{3} \mathrm{PO}_{4}\right) 2.7 \mathrm{~m} \times 1 / 8$ " column. Nitrogen was the carrier gas at $230 \mathrm{kPa}$, and the oven, injector and detector temperatures were 130,250 and $260{ }^{\circ} \mathrm{C}$, respectively. Samples were previously centrifuged (30 min, $13,500 \mathrm{rpm}$, Beckman), filtered $(0.45 \mu \mathrm{m}$, Millipore) and then mixed $(1: 1, v / v)$ with a $0.2 \%$ pivalic acid solution as an internal 
Table 2

Operational conditions and mean values of process parameters.

\begin{tabular}{lll}
\hline Parameter & $\begin{array}{l}\text { Period I } \\
(\mathrm{d} 35-\mathrm{d} 62)^{*}\end{array}$ & $\begin{array}{l}\text { Period II } \\
(\mathrm{d} 95-\mathrm{d} 167)^{*}\end{array}$ \\
\hline STP-FOGW:SC-OFMSW feed ratio (VS:VS) & $0: 1$ & $1: 6$ \\
HRT (d) & 16 & 14.4 \\
OLR (kg VS feed $\left.\mathrm{m}^{-3} \mathrm{~d}^{-1}\right)$ & 4.3 & 5 \\
Total FOG feed content (\%, dry w/w) & 17 & 22 \\
Biogas production $\left(\mathrm{L} \mathrm{d}^{-1}\right)$ & $11.2 \pm 0.4$ & $17 \pm 1$ \\
Methane content in biogas (\%) & $68 \pm 1$ & $72 \pm 2$ \\
Methane yield $\left(\mathrm{m}^{3} \mathrm{CH}_{4} \mathrm{~g} \mathrm{VS}_{\text {added }}^{-1}\right)$ & $0.36 \pm 0.01$ & $0.49 \pm 0.03$ \\
VFA (g L ${ }^{-1}$ ) & $<0.5$ & $<0.5$ \\
pH & $7.8 \pm 1$ & $7.8 \pm 1$ \\
VS reduction (\%) & $70 \pm 2$ & $73 \pm 4$ \\
Total FOG reduction $(\%)$ & $83 \pm 4$ & $91 \pm 3$ \\
Free LCFA mean values $\left(\mathrm{mg} \mathrm{g} \mathrm{TS}^{-1}\right)$ & & \\
Myristic acid & $\mathrm{n} . \mathrm{d}$ & $\mathrm{n} . \mathrm{d}$ \\
Palmitic acid & $2.6 \pm 1$ & $3 \pm 1$ \\
Oleic acid & $1 \pm 1$ & $1.7 \pm 1$ \\
Stearic acid & $0.8 \pm 0.9$ & $0.8 \pm 0.6$ \\
\hline
\end{tabular}

n.d Not detected.

In brackets, considered range in order to calculate mean values of process parameters.

standard. A total sample volume of $1 \mu \mathrm{L}$ was used for chromatography. The detection range was from 0.5 to $8 \mathrm{~g} \mathrm{~L}^{-1}$.

Methane and carbon dioxide content in the biogas were analyzed by means of a Hewlett Packard Chromatograph (HP 5890) equipped with a thermal conductivity detector (TCD) and a Supelco Porapack Q $\left(250^{\circ} \mathrm{C}\right) 3 \mathrm{~m} \times 1 / 8^{\prime \prime}$ column. Helium was the carrier gas at $338 \mathrm{kPa}$, and the oven, injector and detector temperatures were 70,150 and $180^{\circ} \mathrm{C}$, respectively. A total sample volume of $100 \mu \mathrm{L}$ was used for chromatography.

Total FOG content (lipids and also free LCFA) of dried samples $\left(105^{\circ} \mathrm{C}, 24 \mathrm{~h}\right)$ was determined gravimetrically after extraction with $n$-heptane (99\% purity, Panreac, Spain) as organic solvent. FOG extraction was performed in commercial Soxhlet extraction equipment (Extraction system B-811, Büchi, Switzerland).

Free LCFA (myristic, palmitic, oleic and stearic) concentrations were determined by gas chromatography after the total extracted FOG was redissolved with heating in a known n-heptane volume and then filtered $(0.45 \mu \mathrm{m}$, Millipore). A Hewlett Packard Chromatograph (HP 6890) equipped with a flame ionization detector (FID) and a HP-Innowax $(30 \mathrm{~m} \times 0.25 \mathrm{~mm})$ column was used. The carrier gas was Helium ( $500 \mathrm{kPa}$ ) with a split ratio of 15 (column flow: $5 \mathrm{~mL} \mathrm{~min}^{-1}$ ). An initial oven temperature of $260^{\circ} \mathrm{C}$ was maintained for $3 \mathrm{~min}$, then increased to $270{ }^{\circ} \mathrm{C}$ at $10^{\circ} \mathrm{C} \mathrm{min}-1$ and maintained at this temperature for $1 \mathrm{~min}$. Injector and detector temperatures were 250 and $280^{\circ} \mathrm{C}$, respectively. The system was calibrated with commercial solutions (Sigma-Aldrich) of the above mentioned free LCFA within the range of 50 to $1000 \mathrm{mg} \mathrm{L}^{-1}$. A total volume of $5 \mu \mathrm{L}$ was used.

\subsection{Microbial community analysis}

\subsubsection{Sludge sampling and DNA extraction}

Well-homogenized sludge samples were withdrawn from the reactor on days $58,63,67,122,165$ and 178 and stored at $-20{ }^{\circ} \mathrm{C}$ until use. Total genomic DNA was extracted from approximately $500 \mu \mathrm{L}$ of sample using the Fast DNA ${ }^{\circledR}$ Spin kit for soil (MP Biomedicals, USA) in accordance with the manufacturer's instructions. Extracted DNA was maintained at $-20^{\circ} \mathrm{C}$ and used as a template for polymerase chain reaction (PCR-DGGE) amplification.

\subsubsection{PCR amplification}

Microbial 16S rRNA genes were amplified from total genomic DNA using a Taq DNA polymerase kit (Invitrogen, Carlsbad, CA USA). PCR amplification was performed in reaction mixture
$(50 \mu \mathrm{L})$ containing $20 \mathrm{mM}$ Tris- $\mathrm{HCl}(\mathrm{pH} 8.4), 50 \mathrm{mM} \mathrm{KCl}, 3 \mathrm{mM}$ $\mathrm{MgCl}_{2}, 200 \mu \mathrm{M}$ of each of the four deoxynucleoside triphosphates (dNTP) (Invitrogen, Carlsbad, CA, USA), $1.25 \mathrm{U}$ of Taq polymerase, $200 \mathrm{nM}$ of each primer and $1 \mu \mathrm{L}$ of appropriately diluted template DNA. All primers used were synthesised by Invitrogen. Complete bacterial and archaeal 16S rRNA genes were amplified for cloning and sequencing by using the forward primers Bact27-f ( $5^{\prime}$-GTT TGA TCC TGG CTC AG-3') (Weisburg et al., 1991) and Arch109-f (5'-ACK GCT CAG TAA CAC GT-3') (Grosskopf et al., 1998), respectively, and the universal reverse primer Uni1492-r (5'-CGG CTA CCT TGT TAC GAC-3') (Weisburg et al., 1991). The thermocycling program used for amplification was: $95{ }^{\circ} \mathrm{C}$ for $2 \mathrm{~min}$; $95^{\circ} \mathrm{C}$ for $30 \mathrm{~s}, 52^{\circ} \mathrm{C}$ for $40 \mathrm{~s}$ and $72{ }^{\circ} \mathrm{C}$ for $90 \mathrm{~s}$ (30 cycles) and $72{ }^{\circ} \mathrm{C}$ for $5 \mathrm{~min}$. The reactions were finished by decreasing temperature to $4{ }^{\circ} \mathrm{C}$. Regarding DGGE analysis, PCR products were amplified using bacterial 16S rRNA gene primers U968-f (5'-GCA CAA GCG GTG GAG CAT GTG G-3') and L1401-r (Nübel et al., 1996), and archaeal 16S rRNA gene primers A109(T)-f ( $5^{\prime}$-ACT GCT CAG TAA CAC GT-3') (original Grosskopf et al., 1998, third nucleotide changed into T only, Hans G.H.J. Heilig personal communication) and 515-r (5'-ATC GTA TTA CCG CGG CTG CTG GCA-3') (Weisburg et al., 1991) for amplification of the V6-V8 bacterial region and the archaeal V2-V3 region, respectively. A 40-base GC clamp (CGC CCG GGG CGC GCC CCG GGC GGG GCG GGG GCA CGG GGG G) was attached to the primers at the $5^{\prime}$ end. The program used for amplification was as described above but with 35 cycles and an annealing temperature of $56^{\circ} \mathrm{C}$ for the primer pair U968GC-f/ L1401-r. The size and amount of PCR products were estimated by electrophoresis in a $1 \%$ agarose gel (wt/vol), using a 100 bp DNA ladder (MBI Fermentas, Vilnius, Lithuania) followed by ethidium bromide staining.

\subsubsection{DGGE analysis of amplified 16S rRNA genes}

DGGE analysis of the PCR products was performed by using the DCode system (Bio-Rad, Hercules, CA, USA). Gels containing 8\% (wt/vol) polyacrylamide (37.5:1 acrylamide/bis-acrylamide) were used with a denaturing gradient of $30-60 \%$ for Bacteria and $30-50 \%$ for Archaea, with $100 \%$ of denaturant corresponding to $7 \mathrm{M}$ urea and $40 \%$ (vol/vol) formamide. Electrophoresis was performed for $16 \mathrm{~h}$ at $85 \mathrm{~V}$ in a $0.5 \times \mathrm{TAE}$ buffer at $60^{\circ} \mathrm{C}$. DGGE gels were stained with silver nitrate, scanned in an Epson Perfection V750 PRO (Epson, USA) and obtained images imported into the Bionumerics 5.0 software package (Applied Maths, Belgium) for analyses. After image normalization, bands were defined for each sample using the bands search algorithm within the program. Similarity indices $(\mathrm{Si})$ of the compared profiles were calculated from the densitometric curves of the scanned DGGE profiles by using the Pearson product-moment correlation. Community shifts were described as changes in the DGGE profiles of the partial 16S rDNA amplicons. Clustering of patterns was calculated using the unweighted-pair group method using arithmetic mean (UPGMA).

\subsubsection{Cloning and sequencing of microbial $16 S$ rDNA}

Almost-full-length 16S rRNA gene fragments previously amplified by PCR using the primer pairs Arch109f/Uni1492r and Bact27f/ Uni1492r were purified using the PCR clean up kit NucleoSpin Extract II (Macherey-Nagel, Germany). These fragments were incorporated into a pGEM-T vector using the pGEM Easy Vector Systems kit (Promega, Madison, WI, USA). The vector was inserted into Escherichia coli competent cells (Lucigen ${ }^{\circledR}$ Corporation), according to the manufacturer's instructions. Positive transformants were selected and grown in LB media supplemented with ampicillin. Insert size was confirmed by PCR amplification with the pGEM-T-specific primers PG1-f ( $5^{\prime}$-TGG CGG CCG CGG GAA TTC-3') and PG2-r (5'-GGC CGC GAA TTC ACT AGT G-3'). Clones with the correct fragment size were selected and screened by 
amplified ribosomal DNA restriction analysis (ARDRA) with the restriction enzymes MspI, CfoI and AluI (Promega, Madison, WI, USA) and acetylated bovine serum albumin (BSA) at a final concentration of $0.1 \mathrm{mg} \mathrm{mL}^{-1}$. The restriction fragments were analyzed by electrophoresis in a $12 \%$ Poly (NAT) Wide-Mini S- $4 \times 25$ Ready-touse gels (Elchrom Scientific) and visualized with ethidium bromide. Inserts with different ARDRA patterns were compared in DGGE with the band-pattern of the sludge and the ones matching bands in the total community profile further purified (Nucleo Spin Extract II kit) and subjected to DNA sequence analysis. Unique inserts were bidirectionally sequenced with pGEM-T vector-targeted sequencing primers Sp6 (5'-GAT TTA GGT GAC ACT ATA G-3') and T7 (5'-TAA TAC GAC TCA CTA TAG GG-3') at BIOPREMIER (Lisboa, Portugal).

\subsubsection{Phylogenetic analysis}

Partial sequences were assembled by using the CONTIG ASSEMBLY PROGRAM (CAP) application included in the BioEdit v7.0.9 software package (Hall, 1999). Consensus sequences were checked for potential chimera artifacts by the Bellerophon program (http://foo.maths.uq.edu.au/ huber/bellerophon.pl) and sequences determined to be chimeras were removed from further analysis. Sequence similarity for the 16S rRNA gene sequences was analyzed by using the NCBI BLAST search program at http://www.ncbi.nlm. nih.gov/BLAST within the GenBank database.

\section{Results and discussion}

\subsection{Reactor performance}

The current experiment lasted 193 days and the whole reactor performance is presented in Fig. 1. Operational conditions and mean values of several process parameters are also summarized in Table 2.

\subsubsection{Single-substrate stage (SC-OFMSW)-Period I}

During Period I (days 0-62) OLR and HRT were fixed around $4.3 \mathrm{~kg} \mathrm{VS} \mathrm{m} \mathrm{m}^{-3} \mathrm{~d}^{-1}$ (TS feed content was 7\%) and $16 \mathrm{~d}$, respectively, and the addition of SC-OFMSW meant a total FOG feed content around $17 \%$ in TS influent (dry, w/w). Throughout the whole single-substrate stage, reactor performance was stable since no significant fluctuation in biogas production occurred and VFA values were always under $0.5 \mathrm{~g} \mathrm{~L}^{-1}$. Low VS removal (around 58\%) noticed at the beginning of the stage was a consequence of the immediate preceding operational conditions, since previous TS feed content was $14 \%$. In fact, VS destruction increased gradually, achieving an average value around $70 \%$ (Table 2). Mean values for biogas production and methane content in biogas were $11 \mathrm{~L} \mathrm{~d}^{-1}$ and $68 \%$, respectively, which led to a methane yield value of $0.36 \mathrm{~L} \mathrm{~g} \mathrm{VS}_{\text {added }}^{-1}$ (317 $\mathrm{Nm}^{3}$ ton $\mathrm{VS}_{\text {added }}^{-1}$ ).

The results obtained for VS reduction were in the range of those reported in literature for thermophilic anaerobic digestion of OFMSW. For instance, Hartmann and Ahring (2005) obtained 73\% in VS reduction in the thermophilic anaerobic treatment of OFMSW working at comparable operational conditions (OLR $=4 \mathrm{~g} \mathrm{VS} \mathrm{L}^{-1}$ $\mathrm{m}^{-3}$; HRT $=13.5 \mathrm{~d}$ ). However, in the same work, a methane yield of $0.46 \mathrm{~L} \mathrm{CH}_{4} \mathrm{~g} \mathrm{VS}^{-1}$ was achieved, which is noticeable higher than the one obtained in the present study. Also working at $55^{\circ} \mathrm{C}$ and maintaining similar operational conditions, Davidsson et al. (2007) obtained a methane yield of $300-400 \mathrm{Nm}^{3}$ ton $\mathrm{VS}_{\text {added }}^{-1}$ and a VS removal around $80 \%$, showing once more that methane yield obtained for SC-OFMSW ( $317 \mathrm{Nm}^{3}$ ton $\mathrm{VS}_{\text {added }}^{-1}$ ) in the present work is in the lower range of reported values. These differences should be a consequence of the different origins of SC-OFMSW, indicating that
SC-OFMSW used in our work must have a higher content of poorly or non biodegradable material (Mata-Álvarez et al., 1992).

Besides, a comparison between the presented results and the ones obtained in a previous mesophilic experiment carried out in our research group, using the same substrates, is possible since identical operational conditions were established (Martín-González et al., 2010). As expected, thermophilic results obtained during the single-substrate stage revealed improvements in biogas production (42\%), methane yield (50\%) and also VS reduction values (6\%).

FOG content in the effluent, measured from day 38 to day 62 , showed oscillations between 6\% and 9\% (dry, w/w) (Fig. 1), indicating an average value of total FOG removal around 83\%. Palmitic acid was the most abundant free LCFA contained in such FOG samples, followed by oleic and stearic (myristic acid was not detected), and their mean values were, respectively, 2.6, 1 and $0.8 \mathrm{mg} \mathrm{g} \mathrm{TS}^{-1}$. Since SC-OFMSW contain a certain amount of lipids (Table 1 ) these results, as well as the ones obtained during Period II that will be discussed further, are in accordance with previous works (Lalman and Bagley, 2001; Pereira et al., 2002a), that reported accumulations of palmitic acid in LCFA degradation processes and suggested that it would be the main intermediate from the conversion of other LCFA, such as oleic or stearic; all of them primarily contained in both SC-OFMSW and STP-FOGW (Table 1).

\subsubsection{Co-digestion stage (SC-OFMSW with STP-FOGW)-Period II and Period III}

Period II started on day 63 when STP-FOGW were added to SC-OFMSW and fed to the reactor in a 1:6 ratio (VS:VS), which meant $0.7 \mathrm{~g} \mathrm{VS}_{\text {STP-FOGW }} \mathrm{L}_{\text {reactor }}^{-1}$ (STP-FOGW represented $15 \%$ of total influent TS and VS). As a consequence of the addition, total FOG feed content increased from $17 \%$ to $22 \%$ (dry, w/w) and also OLR and HRT were slightly modified (Table 2).

Right after the beginning of Period II, biogas production increased sharply, achieving $14 \mathrm{Ld}^{-1}$ on day 67 (Fig. 1), which led to an initial slight improvement of methane yield $\left(0.39 \mathrm{~L} \mathrm{CH}_{4} \mathrm{~g}\right.$ $\mathrm{VS}_{\text {added }}^{-1}$ ) while, at the same time, VFA remained under $0.5 \mathrm{~g} \mathrm{~L}^{-1}$. Hence, no symptoms of inhibition such as VFA accumulation or decrease in biogas production were observed immediately after feeding STP-FOGW to the reactor; on the contrary, a clear positive effect was noticed.

Further, during days 71 and 72 , short but severe drops in the reactor temperature (reaching $30^{\circ} \mathrm{C}$ for few minutes) occurred as a consequence of operational problems. As a result, both biogas production and methane yield fell at once, registering the lowest values thus far. A decrease in VS removal (56\%) was also noticed later, on day 81 , but, concomitantly, biogas production was yet starting to recover. Moreover, in spite the sudden temperature shocks and its aforementioned consequences, VFA remained under $0.5 \mathrm{~g} \mathrm{~L}^{-1}$, showing that methanogenic population was not seriously affected. Reactor recovery, in terms of methane yield and VS reduction, was observed soon: around day 88, mean values (calculated on a week basis) were, respectively, $0.51 \mathrm{~L} \mathrm{CH}_{4} \mathrm{~g} \mathrm{VS}_{\text {added }}^{-1}$ and $67 \%$. Throughout the rest of Period II VFA were again under $0.5 \mathrm{~g} \mathrm{~L}^{-1}$ and main process parameters were stable with no significant oscillations.

Mean values obtained during Period II (considering only the range between days 95-167) showed an enhancement of 52\% in biogas production ( $17 \mathrm{~L} \mathrm{~d}^{-1}$ ), as well as an increase of $36 \%$ in methane yield $\left(0.49 \mathrm{~L} \mathrm{CH}_{4} \mathrm{~g} \mathrm{VS}_{\text {added }}^{-1}\right)$ as a consequence of STP-FOGW addition, since no other significant operational changes were applied. Again, when comparing results of the current Period II, with the identical mesophilic period performed in a previous experiment (Martín-González et al., 2010), improvements with regard to biogas production (25\%), methane yield (40\%) and VS removal (12\%) are observed. Therefore it is clear that thermophilic 


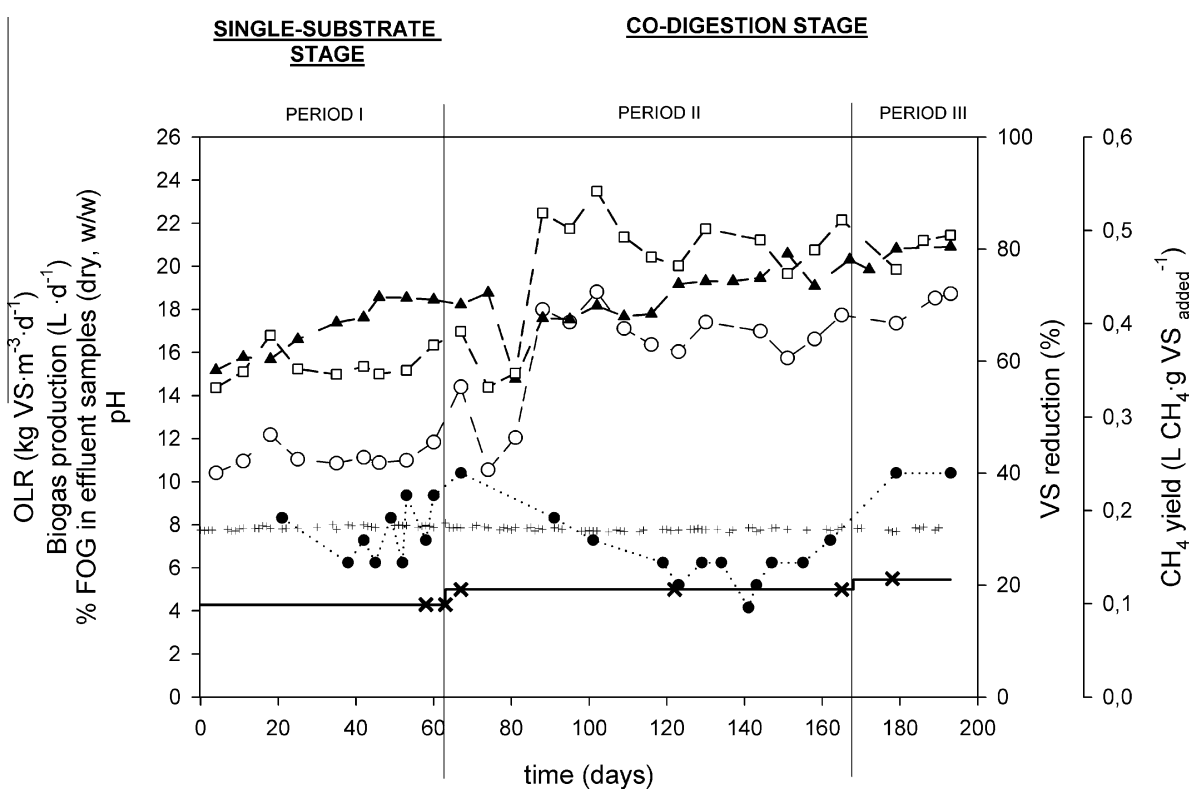

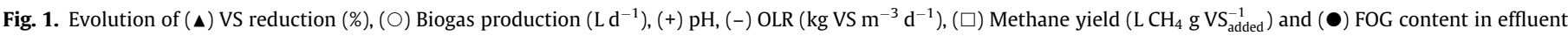
samples $(\%$, dry w/w) during the continuous lab-scale reactor experiment. Time-points of sludge sampling for molecular analysis are indicated with $x$.

conditions increased the yield and efficiency of the anaerobic codigestion of SC-OFMSW with STP-FOGW.

Similar FOG wastes have been tested as a co-substrate with a mixture of primary and thickened sludge at both mesophilic and thermophilic ranges (Kabouris et al., 2009) also showing better results at $52{ }^{\circ} \mathrm{C}$. A slightly higher methane yield value was achieved in comparison to our results ( $512 \mathrm{~mL} \mathrm{~g} \mathrm{VS}_{\text {added }}^{-1}$ ), though it should be noticed that FOG was then $48 \%$ of the total VS load, which represents almost threefold the amount of STP-FOGW fed during Period II ( $15 \%$ of the total influent VS).

No significant differences were noticed in the VS reduction during Period II (73\%), in comparison with Period I (70\%). In contrast, FOG reduction increased significantly achieving $91 \%$, a fact that can explain the remarkable improvement observed in the methane yield. These results seem to be in accordance with other co-digestion experiences dealing with similar organic substrates and lipids. For instance, Li et al. (2002) registered noticeable improvements in both biogas production and lipids removal in a thermophilic process, when increasing the proportion of salad oil and lard added to food waste (from $8 \%$ to $40 \%$ of the influent TS content), without significant variations in VS reduction values. Also Neves et al. (2009a) reported an increase in methane production without significant variations in VS reduction when adding oil pulses up to $12 \mathrm{~g} \mathrm{COD}_{\text {oil }} \mathrm{L}_{\text {reactor }}^{-1}$ to a mixture of cow manure and food waste at mesophilic temperature.

Nevertheless, unstable experiences/stages are also reported, where biogas production ultimately ceases and VFA and LCFA concentrations rise up. In a mesophilic experiment treating synthetic oleic-acid rich wastewater in a continuous reactor, Cavaleiro et al. (2009) observed total VFA around $1000 \mathrm{mg} \mathrm{COD} \mathrm{L}^{-1}$ and total LCFA near $400 \mathrm{mg} \mathrm{COD} \mathrm{g} \mathrm{VS}^{-1}$ when reactor performance became unstable after the OLR was raised up to $31.2 \mathrm{~kg} \mathrm{COD} \mathrm{m}^{-3} \mathrm{~d}^{-1}$. In contrast, in a stable reactor performance, a maximum level of $25 \mathrm{~g} \mathrm{COD}_{\text {LCFA }} \mathrm{kg} \mathrm{TS}^{-1}$ was detected in solid effluent samples when pulses between 0 and $7.7 \mathrm{~g} \mathrm{COD}_{\text {oil }} \mathrm{L}_{\text {reactor }}^{-1}$ of oily wastes from a canned fish industry, were added to a mixture of cow manure and food waste. (Neves et al., 2009b).

In our study, LCFA analyzed from solid effluent samples were very low in comparison with the aforementioned values related to reactor failures. During Period II, mean values of palmitic, oleic and stearic acids (3, 1.7, $0.8 \mathrm{mg} \mathrm{g} \mathrm{TS}^{-1}$, respectively) were very similar to the ones obtained in Period I, showing that there was no significant LCFA accumulation after STP-FOGW addition.

Finally, on day 168, the STP-FOGW:SC-OFMSW ratio was increased to reach 1:4 (VS:VS) and Period III started in order to evaluate the effect of higher amounts of STP-FOGW. As a result, HRT was established at $14 \mathrm{~d}$, OLR was $5.3 \mathrm{~kg} \mathrm{VS} \mathrm{m}^{-3} \mathrm{~d}^{-1}$, total FOG feed content raised to $24 \%$ (dry, w/w) and STP-FOGW meant $22 \%$ of influent TS (1.2 $\left.\mathrm{g} \mathrm{VS}_{\text {STP-FOGW }} \mathrm{L}_{\text {reactor }}^{-1}\right)$. Nevertheless, it should be noticed that Period III was not long enough, thus no mean values were calculated in order to characterize it and only the initial reactor's response could be evaluated. After the raise, a small enhancement in biogas production was noticed in comparison with Period II and VFA still remained under $0.5 \mathrm{~g} \mathrm{~L}^{-1}$. Moreover, although FOG content in effluent samples was higher (10\% on days 179 and 193), palmitic (again the main LCFA) and oleic acids were 2.1 and $1.3 \mathrm{mg} \mathrm{g} \mathrm{TS}^{-1}$ respectively on day 193, remaining in the ranges obtained throughout previous periods. These preliminary results could be explained either because the addition was not high enough to affect biogas production and other process parameters, or because adaptation of microorganisms was this time slower or harder.

\subsection{Microbial community}

Structure and dynamic of the anaerobic consortia developed along the different operation periods (I, II and III) were analyzed by means of DGGE of amplified archaeal and bacterial 16S rDNA gene fragments. Representative archaeal and bacterial profiles obtained for the analyzed samples as well as the correspondent similar dendograms are shown in Fig. 2. According to the displayed DGGE-fingerprints similarities, bacterial community was more affected by the STP-FOGW addition than the archaeal one. The obtained bacterial profiles clustered in two distinct groups, before and after the extended contact with STP-FOGW, while in the archaeal ones, the similarity percentages were close (ranging between 91.9\% and 99.5\%). These results indicate that archaeal populations remained fairly unchanged throughout operation whereas bacterial population structure exhibited a dynamic determined by the introduction of FOG residues in the reactor. The low diversity (measured in terms of DGGE bands) of archaeal community is in 


\section{a}
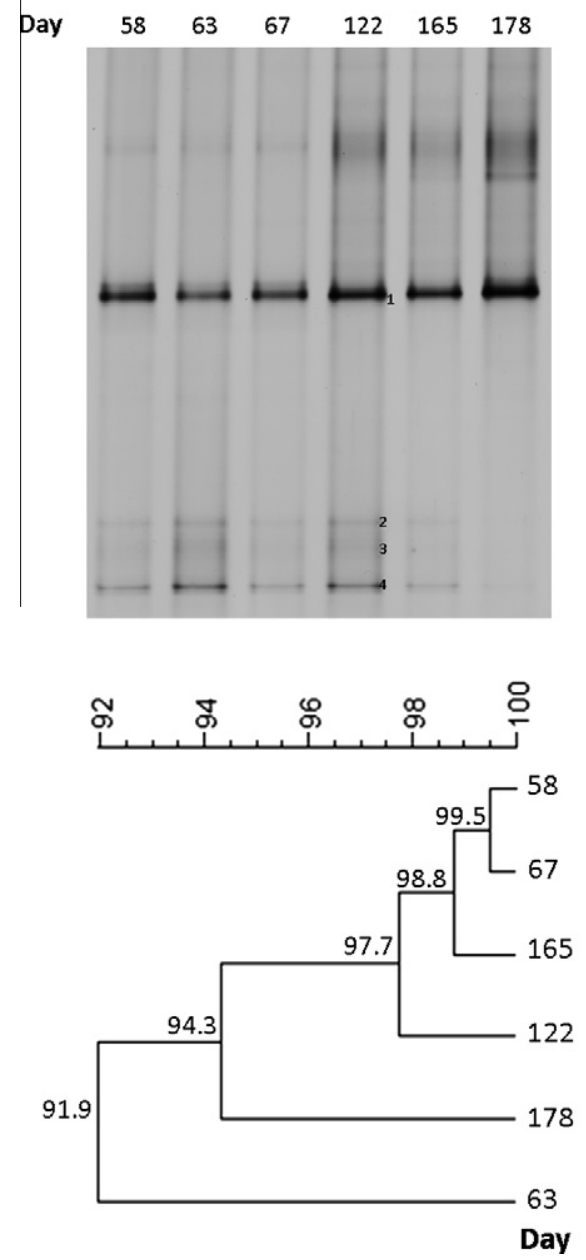

b

b Bacteria
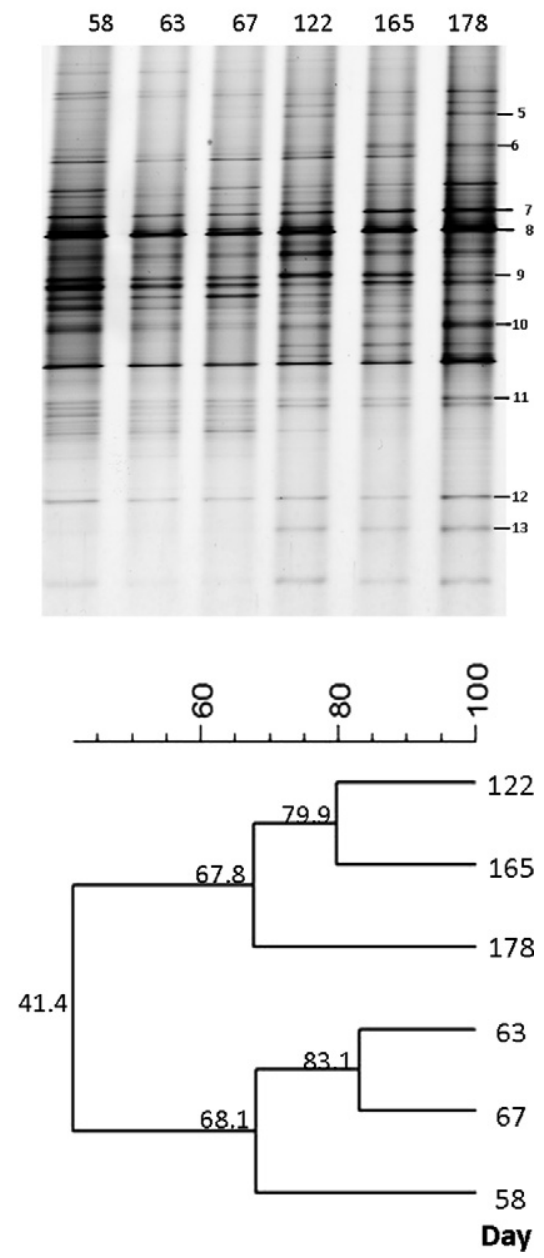

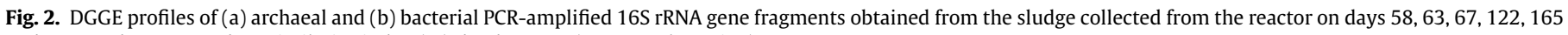
and 178 , and correspondent similarity index (SI) dendograms (UPGMA clustering).

accordance with previous studies (Weiss et al., 2008) that describe a lower diversity in thermophilic when compared to mesophilic anaerobic reactors. In fact, a stable reactor performance was observed during the whole experiment, probably due to the development of an important consortium, acclimated to this type of complex residues.

A more detailed analysis of the microbial community structure developed in the co-digestion stage (SC-OFMSW with STP-FOGW) was further performed through cloning and sequencing of the $16 \mathrm{~S}$ rDNA genes.

\subsubsection{Archaeal community}

The majority of archaeal 16S rRNA gene sequences retrieved (bands 1-3) showed high similarity to those of uncultured clones (99\% similarity), belonging to the phylum Euryarchaeota and assigned to the orders Methanobacteriales, Methanomicrobiales and Methanosarcinales (Table 3). These sequences could be affiliated to clones originated from a high temperature petroleum reservoir (Accession No. HM041912, unpublished), from a thermophilic anaerobic municipal solid waste digester (Accession No. AB114304, Tang et al., 2004) and from a thermophilic anaerobic sludge digester (Accession No. GQ328818, unpublished). These three archaeal clones exhibited also a high level of similarity (more than 97\%) to sequences of cultivated species of Methanobacterium (Methanobacterium sp. OM15), Methanoculleus (Methanoculleus sp. Dm2) and Methanosarcina (Methanosarcina sp. 2214B). The most intense band (band 4) exhibited 99\% similarity to Methanothermobacter wolfeii, a thermophilic hydrogenotrophic methanogen. Although there are some evidences indicating the presence of some species of these genus in thermophilic anaerobic reactors (Hori et al., 2006), to our knowledge this is the first work that describes the presence of Methanothermobacter wolfeii-like organisms in a thermophilic reactor co-digesting municipal solid wastes and fat, oil and grease wastes.

All species of Methanobacterium and Methanoculleus use $\mathrm{H}_{2}$ and $\mathrm{CO}_{2}$ as substrate for methanogenesis. They have been isolated from different sources, such as anaerobic digesters, sewage sludge, manure, among other sources. In fact, Methanobacterium sp. has been identified as an important genus in thermophilic anaerobic reactors treating glycerol-containing wastes (Yang et al., 2008). The presence of members of the genus Methanoculleus in this study is also in agreement with other works where their presence has been described in some thermophilic reactors treating municipal solid wastes (Tang et al., 2004; Weiss et al., 2008). Members of the genus Methanosarcina are able to convert acetate, $\mathrm{CO}_{2}, \mathrm{H}_{2}$, carbon monoxide and methanol to methane. Some of these species were already found in municipal solid waste reactors receiving a complex mixture of residues (Tang et al., 2004; Weiss et al., 2008) and in thermophilic anaerobic digesters fed with manure and pulses of LCFA (Palatsi et al., 2010).

It should be noted that the genus Methanosaeta, which comprises acetoclastic methanogens that uses acetate as the only 
Table 3

Phylogenetic affiliation of the retrieved 16SrRNA gene sequences and correspondent band position in the DGGE profiles.

\begin{tabular}{|c|c|c|c|c|c|}
\hline Clone & Seq length (bp) & DGGE band & Closest relatives (Accession number) ${ }^{\mathrm{a}}$ & Similarity (\%) & Phylum/order ${ }^{\mathrm{b}}$ \\
\hline \multicolumn{6}{|l|}{ Archaea } \\
\hline \multirow[t]{2}{*}{$\mathrm{a} 1$} & 1331 & 1 & Uncultured Methanobacterium sp. clone NRA11 (HM041912) & 99 & Euryarchaeota/Methanobacteriales \\
\hline & & & Methanobacterium sp. OM15, strain OM15(AJ550160) & 98 & \\
\hline \multirow[t]{2}{*}{ a2 } & 1322 & 2 & Uncultured euryarchaeote clone:MAA04 (AB114304) & 99 & Euryarchaeota/Methanomicrobiales \\
\hline & & & Methanoculleus sp. Dm2 (AJ550158) & 97 & \\
\hline \multirow[t]{2}{*}{ a3 } & 1331 & 3 & Uncultured euryarchaeote clone 1B (GQ328818) & 99 & Euryarchaeota/Methanosarcinales \\
\hline & & & Methanosarcina sp. 2214B (AB300208) & 99 & \\
\hline a4 & 1333 & 4 & Methanothermobacter wolfeii (AB104858) & 99 & Euryarchaeota/Methanobacteriales \\
\hline \multicolumn{6}{|l|}{ Bacteria } \\
\hline \multirow[t]{2}{*}{ b1 } & 1456 & 5 & Uncultured bacterium, clone 3wk_3LB16 (AM947544) & 98 & Firmicutes/Clostridiales \\
\hline & & & Clostridium ultunense strain DSM 10521 (GQ461825) & 94 & \\
\hline b2 & 1456 & 6 & Tepidanaerobacter syntrophicus strain OL(AB106354) & 93 & Firmicutes/Thermoanaerobacterales \\
\hline \multirow[t]{2}{*}{ b3 } & 1465 & 7 & Uncultured bacterium clone A55_D21_L_B_F07 (EF559054) & 99 & Bacteroidetes \\
\hline & & & Bacterium sp. OF1(EF148839) & 82 & \\
\hline b4 & 915 & 8 & Uncultured bacterium gene clone B-7 (AB234000) & 100 & Firmicutes \\
\hline \multirow[t]{2}{*}{ b5 } & 1456 & 9 & Uncultured bacterium clone A35_D28_L_B_G12 (EF559211) & 99 & Synergistetes/Synergistia \\
\hline & & & Anaerobaculum mobile strain NGA(NR_028903) & 97 & \\
\hline \multirow[t]{2}{*}{ b6 } & 1454 & 10 & Bacterium enrichment culture clone BBMC-1 (GU476601) & 90 & Firmicutes/Clostridiales \\
\hline & & & Anaerobic bacterium sk.prop8 (AY538172) & 89 & \\
\hline b7 & 1463 & 11 & Uncultured bacterium clone A55_D21_H_B_H04 (EF559060) & 99 & Firmicutes \\
\hline \multirow[t]{2}{*}{ b8 } & 1474 & 12 & Uncultured bacterium clone DC87 (HM107074) & 99 & Bacteroidetes/Bacteroidales \\
\hline & & & Ruminobacillus xylanolyticum(DQ178248) & 88 & \\
\hline b9 & 1430 & 13 & Uncultured bacterium clone B55_F_B_B05 (EF558953) & 91 & Thermotogae/Thermotogales \\
\hline
\end{tabular}

a Genbank accession number.

b Classified using the RDP Naive Bayesian Classifier (Wang et al., 2007).

substrate, was not detected in this work. This absence has been previously reported in thermophilic anaerobic reactors (Tang et al., 2004).

Interestingly, in a recent paper (Goberna et al., 2010) focusing on the co-fermentation of cattle excreta and olive mill wastes at mesophilic and thermophilic conditions, the authors described a burst of Methanobacterium, Methanoculleus, Methanothermobacter and a group of uncultured archaea at $55{ }^{\circ} \mathrm{C}$. The dominance of these groups in thermophilic conditions is in accordance with the results obtained in this work.

\subsubsection{Bacterial community}

Like archaeal clones, the majority of bacterial 16S rRNA gene sequences were similar to several uncultured ribotypes belonging to the phyla Firmicutes, Bacteroidetes, Synergistes and Thermotogae. These sequences assigned to the orders Clostridiales, Bacteroidales, Thermoanaerobacterales, Synergistia and Thermotogales (Table 3). Interestingly, the majority of the sequences obtained matched with uncultured bacteria from the phylum Firmicutes. The members of this phylum are very versatile and participate in the degradation of several complex organic residues, such as lipids, carbohydrates and proteins. Based on these reports, the microorganisms of this phylum presumably have an important role in the degradation of this kind of residues in our system.

Looking at the bacterial DGGE profile (Fig. 2b), three bands increased their intensity after the addition of STP-FOG, namely bands 5,6 and 13 . Clones corresponding to bands 5 and 13 presented high similarity to uncultured bacteria previously detected in thermophilic anaerobic bioreactors (Goberna et al., 2009; Li et al., unpublished results). In addition, clone matching band 5 has $94 \%$ similarity with known cultured species, i.e. Clostridium ultunense. The Clostridiaceae family is, in fact, one of the most common bacterial families in the microbial community of anaerobic digesters. Thus, it is plausible to infer that organisms represented in these DGGE bands can be important in the co-digestion of the two types of wastes used in this work. The cloned sequence illustrated in band 6 presents 93\% similarity to an isolated species belonging to phylum Firmicutes, order Thermoanaerobacteriales, Tepidanaerobacter syntrophicus. This is an anaerobic thermophilic, syntrophic primary alcohol- and lactate-degrading bacteria which was isolated from sludge of thermophilic digesters that decomposed either municipal solid wastes or sewage sludge (Sekiguchi et al., 2006). The sequence from band 9 presented 97\% similarity to Anaerobacterium mobile. This is an anaerobic, thermophilic, and slightly halotolerant bacterium converting organic acids and carbohydrates into acetate, hydrogen, and $\mathrm{CO}_{2}$ (Menes and Muxí, 2002). This species were already detected in thermophilic anaerobic digesters (Goberna et al., 2009; Palatsi et al., 2010). Sequences matching bands 7 and 12 were very similar (99\%) to those of uncultured bacteria; however, they exhibited a low similarity percentage to known isolated species. In particular, the sequence corresponding to DGGE band 12 presented a low similarity percentage (only $88 \%$ ) with Ruminobacillus xylanolyticus, a species isolated from rumen. Until now, these species were not found in thermophilic anaerobic reactors. There is only one work where one sequence could be assigned to a closely related species, i.e. Ruminofilibacter xylanolyticum which is a rumen bacterium involved in digestion of xylan (Kröber et al., 2009).

Interestingly, with the single exception of Tepidanaerobacter syntrophicus, no other syntrophic bacteria typically associated to anaerobic degradation of lipid-rich wastes, was detected in this study. It should be noticed, however, that some weak bands observed on the DGGE profile, not found in the screened clone library thus hindering further phylogenetic assignment, may represent other bacterial species, present in lower numbers, or with lower PCR amplification efficiency.

Although there are some bands corresponding to isolated and well known species, the majority of the bacterial sequences obtained showed high similarity to uncultured anaerobic clones. This is probably related to the lack of knowledge regarding bacterial species in thermophilic reactors co-treating complex residues.

\section{Conclusions}

This study demonstrates that co-digestion of OFMSW with STP-FOGW is a feasible and advantageous treatment option for both wastes. An enhancement of $52 \%$ in biogas production (from 11 to $17 \mathrm{~L} \mathrm{~d}^{-1}$ ), as well as an increase of $36 \%$ in methane yield 
(from 0.36 to $0.49 \mathrm{~L} \mathrm{CH}_{4} \mathrm{~g} \mathrm{VS}_{\text {added }}^{-1}$ ) were observed as a result of STP-FOGW addition. No symptoms of inhibition such as VFA accumulation or decrease in biogas production were observed after feeding STP-FOGW to the reactor. Archaeal community structure remained relatively unchanged along operation whereas bacterial community structure had a dynamic change mainly determined by FOG addition.

\section{Acknowledgements}

The financial support from Fundação para a Ciência e Tecnologia (FCT) and European Community fund FEDER, trough Program COMPETE, in the ambit of the Project FCOMP-01-0124-FEDER007087 (PTDC/BIO/69745/2006) and from Xarxa de Referència en Biotecnologia (Generalitat de Catalunya) is gratefully acknowledged. Lucia Martin thanks Universitat Autònoma de Barcelona for a pre-doctoral fellowship.

\section{References}

Ahring, B.K., Mladenovska, Z., Iranpour, R., Westermann, P., 2002. State of the art and future perspectives of thermophilic anaerobic digestion. Water Sci. Technol. 45 (10), 293-298.

Alves, M.M., Vieira, J.A.M., Pereira, R.M.A., Pereira, M.A., Mota, M., 2001. Effects of lipids and oleic acid on biomass development in anaerobic fixed-bed reactors. Part II: oleic acid toxicity and biodegradability. Water Res. 35 (1), 264-270.

Alves, M.M., Pereira, M.A., Sousa, D.Z., Cavaleiro, A.J., Picavet, M., Smidt, H., Stams, A.J.M., 2009. Waste-lipids to energy: how to optimize methane production from long chain fatty acids (LCFA). Microb. Biotechnol. 2 (5), 538-550.

APHA, AWWA, WPCF, 1999. Standard Methods for the Examination of Water and Wastewater, 20th ed. American Public Health Association, American Water Works Association, Water Environment Federation, Washington, DC.

Briones, A., Raskin, L., 2003. Diversity and dynamics of microbial communities in engineered environments and their implications for process stability. Curr. Opin. Biotechnol. 14 (3), 270-276.

Cavaleiro, A.J., Salvador, A.F., Alves, J.I., Alves, M., 2009. Continuous high rate anaerobic treatment of oleic acid based wastewater is possible after a step feeding start-up. Environ. Sci. Technol. 43 (8), 2931-2936.

Cavinato, C., Fatone, F., Bolzonella, D., Pavan, P., 2010. Thermophilic anaerobic codigestion of cattle manure with agro-wastes and energy crops: Comparison of pilot and full scale experiences. Bioresour. Technol. 101 (2), 545-550.

Creamer, K.S., Chen, Y., Williams, C.M., Cheng, J.J., 2010. Stable thermophilic anaerobic digestion of dissolved air flotation (DAF) sludge by co-digestion with swine manure. Bioresour. Technol. 101 (9), 3020-3024.

Davidsson, A., Gruvberger, C., Christensen, T.H., Hansen, T.L., Jansen, J.L., 2007. Methane yield in source-sorted organic fraction of municipal solid waste. Waste Manage. 27 (3), 406-414

De Baere, L., Mattheeuws, B., 2010. Anaerobic Digestion of MSW in Europe. BioCycle 51 (2), 24-27.

Ferrer, I., Vazquez, F., Font, X., 2010. Long term operation of a thermophilic anaerobic reactor: Process stability and efficiency at decreasing sludge retention time. Bioresour. Technol. 101 (9), 2972-2980.

Goberna, M., Insam, H., Franke-Whittle, I.H., 2009. Effect of biowaste sludge maturation on the diversity of thermophilic bacteria and archaea in an anaerobic reactor. Appl. Environ. Microbiol. 75 (8), 2566-2572.

Goberna, M., Gadermaier, M., García, C., Wett, B., Insam, H., 2010. Adaptation of methanogenic communities to the cofermentation of cattle excreta and olive mill wastes at 37 and $55^{\circ} \mathrm{C}$. Appl. Environ. Microbiol. 76, 6564-6571.

Grosskopf, R., Janssen, P.H., Liesack, W., 1998. Diversity and structure of the methanogenic community in anoxic rice paddy soil microcosms as examined by cultivation and direct 16S rRNA gene sequence retrieval. Appl. Environ. Microbiol. 64, 960-969.

Hall, T.A., 1999. BioEdit: a user-friendly biological sequence alignment editor and analysis program for Windows 95/98/NT. Nucleic Acids Symp. Ser. 41, 95-98.

Hartmann, H., Ahring, B.K., 2005. Anaerobic digestion of the organic fraction of municipal solid waste: influence of co-digestion with manure. Water Res. 39 (8), 1543-1552.

Hori, T., Haruta, S., Ueno, Y., Ishii, M., Igarashi, Y., 2006. Dynamic transition of methanogenic population in response of the concentration of volatile fatty acids in thermophilic anaerobic digester. Appl. Environ. Microbiol. 72, 1623-1630.
Hwu, C.S., Tseng, S.K., Yuan, C.Y., Kulik, Z., Lettinga, G., 1998. Biosorption of longchain fatty acids in uasb treatment process. Water Res. 32 (5), 1571-1579.

Kabouris, J.C., Tezel, U., Pavlostathis, S.G., Engelmann, M., Dulaney, J.A., Todd, A.C., Gillette, R.A., 2009. Methane recovery from the anaerobic codigestion of municipal sludge and FOG. Bioresour. Technol. 100, 3701-3705.

Kim, M., Ahn, Y.H., Speece, R.E., 2002. Comparative process stability and efficiency of anaerobic digestion; mesophilic vs. thermophilic. Water Res. 36 (17), 43694385.

Kröber, M., Thomas, T., Diaz, N.N., Goesmannb, A., Jaenickeb, S., Kraused, L., Millera, D., Runteb, K.J., Viehöverc, P., Pühlera, A., Schlüter, A., 2009. Phylogenetic characterization of a biogas plant microbial community integrating clone library $16 S-r D N A$ sequences and metagenome sequence data obtained by 454pyrosequencing. J. Biotechnol. 142, 38-49.

Lalman, J.A., Bagley, D.M., 2001. Anaerobic degradation and methanogenic inhibitory effects of oleic and stearic acids. Water Res. 35 (12), 2975-2983.

Li, T., Bouchez, T., Mazeas, L., unpublished results. Microbial functional groups in a thermophilic anaerobic solid waste digestor revealed by stable isotope probing.

Li, Y.Y., Sasaki, H., Seki, K., Kamigochi, I., 2002. High rate fermentation of lipid-rich food wastes by a high-solids co-digestion process. Water Sci. Technol. 45 (12), 143-150.

Martín-González, L., Colturato, L.F., Font, X., Vicent, T., 2010. Anaerobic co-digestion of the organic fraction of municipal solid waste with FOG waste from a sewage treatment plant: recovering a wasted methane potential and enhancing the biogas yield. Waste Manage. 30, 1854-1859.

Mata-Âlvarez, J., Llabrés, P., Cecchi, F., Pavan, P., 1992. Anaerobic digestion of the barcelona central food market organic wastes: experimental study. Bioresour. Technol. 39, 39-48.

Menes, R.J., Muxí, L., 2002. Anaerobaculum mobile sp. nov., a novel anaerobic, moderately thermophilic, peptide-fermenting bacterium that uses crotonate as an electron acceptor, and emended description of the genus Anaerobaculum. Int. J. Syst. Evol. Microbiol. 52, 157-164.

Neves, L., Oliveira, R., Alves, M.M., 2009a. Co-digestion of cow manure, food waste and intermittent input of fat. Bioresour. Technol. 100 (6), 1957-1962.

Neves, L., Oliveira, R., Alves, M.M., 2009b. Fate of LCFA in the co-digestion of cow manure, food waste and discontinuous addition of oil. Water Res. 43 (20), 5142-5150.

Nübel, U., Engelen, B., Felske, A., Snaidr, J., Wieshuber, A., Amann, R.I., Ludwig, W., Backhaus, H., 1996. Sequence heterogeneities of genes encoding 16S rRNAs in Paenibacillus polymyxa detected by temperature gradient gel electrophoresis. J. Bacteriol. 178, 5636-5643.

Palatsi, J., Illa, J., Prenafeta-Boldu, F.X., Laureni, M., Fernandez, B., Angelidaki, I., Flotats, X., 2010. Long-chain fatty acids inhibition and adaptation process in anaerobic thermophilic digestion: batch tests, microbial community structure and mathematical modelling. Bioresour. Technol. 101 (7), 2243-2251.

Pereira, M.A., Pires, O.C., Mota, M., Alves, M.M., 2002a. Anaerobic degradation of oleic acid by suspended and granular sludge: identification of palmitic acid as a key intermediate. Water Sci. Technol. 45 (10), 139-144.

Pereira, M.A., Roest, K., Stams, A.J.M., Mota, M., Alves, M., Akkermans, A.D.L., 2002b. Molecular monitoring of microbial diversity in expanded granular sludge bed (EGSB) reactors treating oleic acid. FEMS Microbiol. Ecol. 41 (2), 95-103.

Pereira, M.A., Sousa, D.Z., Mota, M., Alves, M.M., 2004. Mineralization of LCFA associated with anaerobic sludge: kinetics, enhancement of methanogenic activity, and effect of VFA. Biotechnol. Bioeng. 88 (4), 502-511.

Sekiguchi, Y., Imachi, H., Susilorukmi, A., Muramatsu, M., Ohashi, A., Harada, H., Hanada, S., Kamagata, Y., 2006. Tepidanaerobacter syntrophicus gen. nov., sp. nov., an anaerobic, moderately thermophilic, syntrophic alcohol- and lactatedegrading bacterium isolated from thermophilic digested sludges. Int. J. Syst. Evol. Microb. 56, 1621-1629.

Sousa, D.Z., Pereira, M.A., Stams, A.J.M., Alves, M.M., Smidt, H., 2007. Microbial communities involved in anaerobic degradation of unsaturated or saturated long-chain fatty acids. Appl. Environ. Microbiol. 73 (4), 1054-1064.

Tang, Y., Shigematsu, T., Ikbal, T., Morimura, S., Kida, K., 2004. The effects of microaeration on the phylogenetic diversity of microorganisms in a thermophilic anaerobic municipal solid-waste digester. Water Res. 38, 2537-2550.

Wang, Q.G., Garrity, M., Tiedje, J.M., Cole, J.R., 2007. Naïve Bayesian classifier for rapid assignment of rRNA sequences into the new bacterial taxonomy. Appl. Environ. Microbiol. 73 (16), 5261-5267.

Weisburg, W.G., Barns, S.M., Pelletier, D.A., Lane, D.J., 1991. 16S ribosomal DNA amplification for phylogenetic study. J. Bacteriol. 173, 697-703.

Weiss, A., Jérôme, V., Freitag, R., Mayer, H.K., 2008. Diversity of the resident microbiota in a thermophilic municipal biogas plant. Appl. Microbiol. Biotechnol. 81, 163-173.

Yang, Y., Tsukahara, K., Sawayama, S., 2008. Biodegradation and methane production from glycerol-containing synthetic wastes with fixed-bed bioreactor under mesophilic and thermophilic anaerobic conditions. Process. Biochem. 43, 362-367. 